\title{
O TRABALHO ESCRAVO CONTEMPORÂNEO ANALISADO SOB A - PERSPECTIVA DA DIGNIDADE DA PESSOA HUMANA ENQUANTO DIREITO DA PERSONALIDADE
}

\author{
Danieli A. C. Leite $^{1}$ \\ Renato Bernardi ${ }^{2}$
}

RESUMO: No presente artigo estuda-se o trabalho escravo contemporâneo sob a perspectiva da dignidade da pessoa humana enquanto direito da personalidade, buscando promover a conscientização na luta contra a escravidão moderna, por meio da qual direitos fundamentais são suprimidos, como a liberdade, a dignidade, a honra e o direito de viver, contrariando princípios fundamentais do Estado Democrático de Direito. Dentro da problemática, busca-se expor a ideia de que o Direito do Trabalho desempenha função de promover a melhoria nas condições laborais, garantindo qualidade de vida e efetivando a dignidade humana. A pesquisa segue método dedutivo, com técnicas de pesquisa bibliográfica.

Palavras-chave: Direitos da personalidade; dignidade; liberdade; justiça social; trabalho escravo.

\section{THE CONTEMPORARY SLAVE LABOR FROM THE PERSPECTIVE OF HUMAN DIGNITY WHILE RIGHT OF PERSONALITY}

\begin{abstract}
This article examines the contemporary slave labor from the perspective of human dignity while right of personality, seeking promote awareness in the fight against modern slavery, by means of which fundamental rights are suppressed, as freedom, dignity, honor and the right to live, contrary to fundamental principles of the democratic State of law. Inside the issue, seek to expose the idea that labour law plays role of promoting improvement in working conditions, ensuring quality of life and quantity of human dignity. The research follows deductive method, with bibliographic research techniques.
\end{abstract}

Keys-words: Personality rights; dignity; freedom; social justice; slave labor.

\section{Introdução}

\footnotetext{
${ }^{1}$ Mestra em Ciência Jurídica pela Universidade Estadual do Norte do Paraná (UENP). Mestranda em Ensino pela mesma instituição. Especialista em Direito do Trabalho. Especialista em Educação Ambiental. Professora Universitária. Membro do Grupo de Pesquisa Intervenção do Estado na Vida das Pessoas - GP INTERVEPES, UENP Jacarezinho. Advogada.

${ }^{2}$ Doutor em Direito do Estado (sub-área Direito Tributário) pela Pontifícia Universidade Católica de São Paulo PUC-SP. Professor efetivo dos cursos de Pós-Graduação stricto sensu - Mestrado e Doutorado - e do curso de Graduação da Faculdade de Direito do Centro de Ciências Sociais Aplicadas da Universidade Estadual do Norte do Paraná - UENP, Campus de Jacarezinho. Coordenador do Grupo de Pesquisa Intervenção do Estado na Vida das Pessoas - GP INTERVEPES, UENP Jacarezinho. Procurador do Estado de São Paulo desde 1994.
} 
O presente artigo aborda o contexto de trabalho escravo contemporâneo, a partir da perspectiva da dignidade da pessoa humana enquanto direito da personalidade, contemplando um viés de análise do texto constitucional, com o fim de promover a conscientização na luta contra a escravidão moderna, por meio da qual direitos fundamentais são suprimidos, como a liberdade, a dignidade, a honra e o direito de viver, contrariando princípios fundamentais do Estado Democrático de Direito.

Sendo assim, pensar o trabalho escravo atualmente, não é pensar em correntes e masmorras, mas, ter à mente humilhações constantes, ambiente insalubre, péssimas condições de transporte, supressão de direitos trabalhistas mínimos, além de ausência de condições de higiene. Todas as características mencionadas anteriormente reduzem o trabalhador à condição análoga à de escravo, considerando que submetem o trabalhador a situações deploráveis de vida, consequentemente ferindo direitos constitucionalmente garantidos.

Sob essa ótica, verifica-se que os direitos da personalidade estão sendo gravemente feridos no contexto de trabalho escravo contemporâneo, ainda que, não seja mais apenas a liberdade o foco da restrição, mas também, outras formas de coação, como a ofensa à liberdade de locomoção e a violação à dignidade da pessoa humana.

Dessa forma, resta evidente que o bem jurídico a ser tutelado no combate ao trabalho escravo contemporâneo é a dignidade da pessoa humana, pois, o labor realizado sob a coordenação do empregador escravocrata, afronta esse direito da personalidade que também é princípio basilar do Estado Democrático de Direito

O objetivo geral da pesquisa é analisar o trabalho escravo à luz da dignidade da pessoa humana, com base, principalmente, na concepção de trabalho digno. Ademais, aduz-se que é somente por meio do trabalho digno que se promove a verdadeira cidadania e a dignidade plena da pessoa humana. Destarte, a valorização do trabalho é elemento imprescindível para a valorização do próprio ser humano.

Neste viés, o referencial teórico adotado se valeu do conceito de dignidade em Kant, Carlos Alberto Bittar, e da obra de Ingo Sarlet, além do amparo da Declaração Universal de Direitos Humanos e dos fundamentos da República Federativa do Brasil, no art. $1^{\circ}$, inciso III, da Constituição da República de 1988. No intuito de ilustrar a influência dos direitos da personalidade enquanto direitos fundamentais no direito do trabalho, tratou-se de utilizar obras que possuem a linha de pensamento do direito constitucional do trabalho, das autoras Gabriela Delgado e Lívia Miráglia. 


\section{O TRABALHO ESCRAVO CONTEMPORÂNEO ANALISADO SOB A -PERSPECTIVA DA DIGNIDADE DA PESSOA HUMANA ENQUANTO DIREITO DA PERSONALIDADE}

Por fim, em que pese seja exposto um contexto em que é relatada uma realidade escravista e exploratória do ser humano, que deve ser banida da sociedade, o intuito é contemplar o exercício do trabalho em condições dignas, revelando que o trabalho é algo benéfico ao ser humano, contrário ao sofrimento, reafirmando a máxima “O trabalho dignifica o homem”.

Por fim, para coleta e análise dos materiais pesquisados, utilizaram-se como técnicas de pesquisa o método dedutivo, pois que se partiu de uma visão geral acerca do princípio da dignidade, adentrando-se no conceito de trabalho escravo, com técnicas de pesquisa bibliográfica, com o emprego de obras referentes aos pesquisadores da temática proposta, bem como de artigos e revistas científicas direcionadas.

\section{Dignidade da pessoa humana como direito da personalidade}

A construção teórica dos direitos da personalidade teve origem nas doutrinas germânicas e francesas, na segunda metade do século XIX, sendo nas constituições pós-guerra que se estabeleceu previsão legal.

Os direitos da personalidade são considerados direitos humanos, sua afirmação assegura a inclusão, e, por consequência, o desenvolvimento do Estado Social.

Diante disso, conforme leciona Gustavo Tepedino (2004, p. 25), temos que:

A categoria dos direitos da personalidade chegou a ser negada por se entender que a vida, a saúde, a honra, não faziam parte do ter do indivíduo, mas do ser, por isso, conflitante com a noção de direito subjetivo, tendente a direitos patrimoniais.

Nesse ínterim, justamente por objetivar a proteção eficaz da pessoa humana, é que os direitos da personalidade são dotados de características especiais, como a irrenunciabilidade, intransmissibilidade, imprescritibilidade, impenhorabilidade, extrapatrimonialidade, oponíveis erga omnes. (ARAÚJO, 2013, p. 38)

Os direitos da personalidade são direitos essenciais à existência humana, se traduzindo na concretização da condição ou maneira de ser da pessoa.

No tocante a aposição da pessoa humana, Daniel Sarmento (2004, p. 111) leciona que: 
O princípio da dignidade exprime, por outro lado, a primazia da pessoa humana sobre o Estado. A consagração do princípio importa no reconhecimento de que a pessoa é o fim, e o Estado não mais do que um meio para a garantia e promoção dos seus direitos fundamentais.

A Constituição da República de 1988, promovida pelo caráter de humanização concebeu a proteção dos direitos da personalidade, a fim de, a partir da valorização do homem se garantisse os direitos sociais.

A atenção dispensada pelo Constituinte aos direitos da personalidade, uma vez que tais direitos estão todos, de forma explícita ou implícita, tutelados por normas constitucionais de direitos fundamentais, mostra-se no sentido de ampliação do reconhecimento dos direitos privados como explica Carlos Alberto Bittar (2008, p. 60):

As mudanças ocorridas no cenário político favoreceram a expansão dos movimentos de defesa dos direitos fundamentais do homem, surgindo daí, em vários setores, diferentes posicionamentos pela extensão desse campo, com a enunciação, por expresso, de inúmeros outros direitos e com a instituição de mecanismos destinados a fazê-los prosperar frente ao Estado.

Segue entendimento semelhante, Cláudio Ari Mello (2003, p. 89) ao sustentar que:

[...] o sistema de proteção jurídica dos direitos da personalidade fundase sobre duas cláusulas gerais, o princípio constitucional da dignidade da pessoa humana, do artigo $1^{\circ}$, III, da Constituição Federal e o artigo 12 do Código Civil de 2002, a primeira funcionando como a fonte normativa material da tutela jurídica da personalidade, e a seguinte, como cláusula de abertura formal do sistema. Essa circunstância determina ao sistema de tutela jurídica da personalidade uma permanente articulação entre o direito constitucional e o direito privado.

Para Carlos Alberto Bittar (2008, p. 11), “os direitos da personalidade são dotados de caracteres especiais, para uma proteção eficaz à pessoa humana, em função de possuírem, como objeto, os bens mais elevados da pessoa humana”, e complementa:

Por isso é que o ordenamento jurídico não pode consentir que deles se despoje o titular, emprestando-lhes caráter essencial. Daí, são, de início, direitos intransmissíveis, indispensáveis, restringindo-se à pessoa titular manifestando-se desde o nascimento (Código Civil, art. $2^{\circ}$ ).

O referido autor, na sequência, apresenta os direitos da personalidade, “como direitos inatos, que estão ou não positivados, já que derivam do princípio da dignidade da pessoa humana”. (BITTAR, 2008, p. 11). 


\section{O TRABALHO ESCRAVO CONTEMPORÂNEO ANALISADO SOB A -PERSPECTIVA DA DIGNIDADE DA PESSOA HUMANA ENQUANTO DIREITO DA PERSONALIDADE}

Neste contexto, tem-se que para garantir à pessoa condições mínimas à sua existência e desenvolvimento de sua personalidade, é necessário que os direitos fundamentais sejam dotados de plena eficácia de modo que sua efetividade não se restrinja apenas no plano teórico.

Por fim, há que ressaltar que todos os direitos da personalidade são espécie de direitos humanos, porquanto espécie de direitos fundamentais, ainda que relacionados à integridade física e moral da pessoa humana.

\section{A Dignidade da Pessoa Humana como princípio fundamental}

A dignidade da pessoa humana consolida-se no art. $1^{\circ}$, III, da Constituição, como um dos fundamentos da República Federativa do Brasil e do Estado Democrático de Direito. O referido artigo elenca ainda em seus incisos II e IV a cidadania e os valores sociais do trabalho e da livre iniciativa, respectivamente.

Consoante ensina Gabriela Delgado (2006, p. 206):

[...] a perspectiva da Constituição Federal de 1988 é a de defesa e garantia dos direitos dos cidadãos, com base numa concepção ampliada dos Direitos Humanos, estabelecendo o compromisso do Estado, da sociedade e do governo de zelar por tais direitos.

A dignidade como fundamento da República Federativa do Brasil se assenta na existência digna (art. 170, caput, CR), que trata dos princípios gerais da atividade econômica, adverte que "a ordem econômica, fundada na valorização do trabalho humano e na livre iniciativa, tem por fim assegurar a todos existência digna, conforme os ditames da justiça social...”, ao passo que a dignidade como princípio preconiza o direito à dignidade (art. 227, caput, CR). Em que pese o texto constitucional ter valorizado a ordem econômica e o sistema econômico do capitalismo, ele ressaltou a prioridade do trabalho e a dignidade humana.

Para Uadi Lammêgo Bulos, a dignidade da pessoa humana é valor constitucional supremo, vejamos:

agrega em torno de si a unanimidade dos demais direitos e garantias fundamentais do homem. Envolve o direito à vida, os direitos pessoais tradicionais, mas também os direitos sociais, os direitos econômicos, os direitos educacionais, bem como as liberdades públicas em geral. (2007, p. 83).

Para Ingo Wolfgang Sarlet a definição de dignidade da pessoa humana é a seguinte:

A qualidade intrínseca e distintiva de cada ser humano que o faz merecedor do mesmo respeito e consideração por parte do Estado e da 
Comunidade, implicando, neste sentido, um complexo de direitos e deveres fundamentais que assegurem a pessoa tanto contra todo e qualquer ato de cunho degradante e desumano, como venham a lhe garantir as condições existenciais mínimas para uma vida saudável, além de propiciar e promover sua participação ativa e corresponsável nos destinos da própria existência e da vida em comunhão com os demais seres humanos. (2001, p. 60).

Como vida saudável, o referido autor utiliza-se da definição da Organização Mundial da Saúde - OMS, conforme segue:

Um completo bem-estar físico, mental e social, parâmetro este que, pelo seu reconhecimento amplo no âmbito da comunidade internacional, poderia igualmente servir como diretriz mínima a ser assegurada pelos Estados. (Ibid., p. 60).

O referido autor, lembra que "o ponto de ligação entre a pobreza, a exclusão social e os direitos sociais, reside justamente no respeito pela proteção da dignidade humana”. (Ibid., p. 93).

A dignidade da pessoa humana como fundamento destaca que o Estado existe em função da pessoa humana e não o oposto, e que o ser humano constitui o objetivo máximo da atividade estatal. Enquanto o princípio da dignidade da pessoa humana está diretamente vinculado a direitos fundamentais, como o direito à vida, à liberdade, à integridade física e psíquica, à intimidade, à honra, à imagem, ao trabalho, à saúde, à moradia, dentre outros.

Desse modo, conforme entendimento de Alexy (2008, p. 107), a dignidade da pessoa humana se distingue entre regras e princípios. Sendo assim, a dignidade como fundamento se trata de uma regra jurídica absoluta, é uma norma que sempre é satisfeita ou não satisfeita. Se a regra vale, deve-se então agir exatamente como ela determina.

Nesse contexto, a dignidade como princípio se trata de um "mandamento de otimização", que pode ser realizada em graus variados, prescrevendo algo relacionado à proteção e à promoção da dignidade da pessoa, considerando-se as possibilidades fáticas e jurídicas, enquanto que as regras expressam prescrições imperativas de conduta.

Ressalte-se, que de acordo com o art. $1^{\circ}$, CF, a existência digna é medida pela quantidade de oportunidades proporcionadas aos indivíduos. Todavia, não existe dignidade quando há privação de direitos em qualquer uma das fases da vida humana, por essa razão, o trabalho análogo às condições de escravo são considerados indignos, vez que limita a dignidade do indivíduo e afronta a dignidade enquanto princípio. 


\section{O TRABALHO ESCRAVO CONTEMPORÂNEO ANALISADO SOB A -PERSPECTIVA DA DIGNIDADE DA PESSOA HUMANA ENQUANTO DIREITO DA PERSONALIDADE}

Nesse diapasão, importante não olvidar que a efetividade dos direitos dos trabalhadores também se dará através dos Tribunais Regionais do Trabalho, por meio de Reclamações Trabalhistas ou pela ação dos membros do Ministério Público do Trabalho, apurando as inúmeras denúncias de ocorrência de trabalho escravo. No entanto, para que haja esmero no combate à escravidão moderna, é necessário que todos os procedimentos sejam pautados num processualismo que contemple as minorias e o sujeito de direitos que busca a proteção da justiça e a inclusão social. Esse processualismo contemporâneo, que abriga a sociedade menos favorecida, é denominado neoprocessualismo.

Segundo Cambi (2009, p. 117), o neoprocessualismo, fruto do neoconstitucionalismo, apresenta um novo método de compreensão jurídica, que supera o legalismo preso somente à forma, para aplicar uma nova forma de interpretação e de aplicação do direito, calcada na Constituição.

O neoprocessualismo permite que os conceitos vagos elencados no art. 149 do Código Penal, “trabalhos forçados”, “jornada exaustiva” e “condições degradantes de trabalho”, sejam interpretados de modo que valorizem a dignidade da pessoa humana, ou seja, sob a ótica dos direitos fundamentais.

Diante deste entendimento, resta-nos evidente a importância da aplicação dos direitos fundamentais aos direitos trabalhistas, envolvendo a tutela dos trabalhadores a partir dos seus direitos básicos, e não somente a partir da legislação trabalhista.

De acordo com Silva (2010, p. 68) conclui-se, portanto, que na qualidade de princípio normativo fundamental (CF, art. $1^{\circ}$, III), a dignidade da pessoa humana atrai o conteúdo de todos os direitos fundamentais do homem, exigindo o reconhecimento e a realização dos direitos fundamentais de todas as dimensões, de sorte que não há dignidade sem que se reconheçam ao indivíduo os direitos fundamentais que lhe são inerentes pela simples condição de ser humano.

Logo, considerando que resta-nos evidente que o trabalho proporciona inclusão social, a dignidade humana deve ser protegida prioritariamente. Neste sentido, Rizzato Nunes (2007, p. 129) afirma que, “a dignidade humana do trabalhador é um valor preenchido a priori, isto é, todo ser humano tem dignidade só pelo fato já de ser pessoa. A busca da justiça deve ter como base o ser humano”.

Diante deste entendimento, resta-nos evidente que o principal fundamento para a vedação de todas as espécies de trabalho análogo ao de escravo é a dignidade da pessoa humana. 


\section{0 trabalho escravo analisado sob a perspectiva da dignidade da pessoa humana}

O trabalho alimenta a dignidade da pessoa humana, vez que estimula o convívio social e a autoestima, além de enobrecer a pessoa. Em contrapartida, o trabalho em condições análogas às de escravo exprime uma mazela social enrustida pela modernidade, que suga e explora o trabalhador pobre e necessitado, como se homem não fosse, e contraria a aplicação dos direitos sociais inerentes aos trabalhadores.

Segundo José Moura Gonçalves Filho, responsável pelo prefácio do livro Homens Invisíveis, de Fernando Braga da Costa (2004, p. 14):

Não é mais livre quem manda do que quem obedece: somos irmãos na mesma miséria, e uma saída pede que todos lamentem suas armaduras de classe e a tristeza de não vivermos numa comunidade de troca, conversa e mútuo enriquecimento.

Em homenagem ao $90^{\circ}$ aniversário da Rerum Novarum, o Papa João Paulo II escreveu a Encíclica Laborem Exercens (1981, p. 27), sobre o trabalho humano, que no capítulo 9, denominado Trabalho e Dignidade da Pessoa, preocupa-se com a fadiga do trabalhador e a sua dignidade, no seguinte sentido:

Esta fadiga é um fato universalmente conhecido, porque universalmente experimentado. Sabem-nos os homens que fazem um trabalho braçal, executado por vezes em condições excepcionalmente difíceis; sabem-nos os que labutam na agricultura, os quais empregam longas jornadas no cultivar a terra, que por vezes apenas "produz espinhos e abrolhos” \{Hbr 6,8; cf. Gên. 3,18\} \{...\} É sabido, ainda, que é possível usar de muitas maneiras do trabalho contra o homem, que se pode mesmo punir o homem com o recurso ao sistema dos trabalhos forçados nos lager (campos de concentração), que se pode fazer do trabalho um meio de opressão do homem e que, enfim, se pode explorar, de diferentes maneiras, o trabalho humano, ou seja, o homem do trabalho. Tudo isto depõe a favor da obrigação moral de unir a laboriosidade como virtude com a ordem social do trabalho, o que há de permitir ao homem "tornar-se mais homem” no trabalho, e não há degradar-se por causa do trabalho, desgastando não apenas as forças físicas (o que, pelo menos até certo ponto, é inevitável), mas sobretudo menosprezando a dignidade e subjetividade que lhe são próprias.

Considerando que o trabalho escravo é concretizado na junção das modalidades trabalho forçado ou obrigatório, realizado em condições degradantes, resta evidenciada a violação dos direitos sociais, e, por consequência, também, a “dignidade da pessoa humana”, 


\section{O TRABALHO ESCRAVO CONTEMPORÂNEO ANALISADO SOB A -PERSPECTIVA DA DIGNIDADE DA PESSOA HUMANA ENQUANTO DIREITO DA PERSONALIDADE}

dignidade esta, elevada a princípio fundamental, conforme o disposto no inciso III do art. $1^{\circ} \mathrm{da}$ Constituição da República Federativa do Brasil de 1988. Sendo assim, trabalharemos com o conceito de dignidade, tão bem mensurado por Ingo Wolfgang Sarlet:

Dignidade é a qualidade intrínseca e distintiva de cada ser humano que o faz merecedor do mesmo respeito e consideração por parte do Estado e da comunidade, implicando, neste sentido, um complexo de direitos e deveres fundamentais que assegurem a pessoa tanto contra todo e qualquer ato de cunho degradante e desumano, como venham a lhe garantir as condições existenciais mínimas para uma vida saudável, além de propiciar e promover sua participação ativa e corresponsável nos destinos da própria existência e da vida em comunhão com os demais seres humanos.”

Sob a perspectiva da dignidade da pessoa humana, a manutenção de trabalhadores exercendo seu labor em condições análogas à escravidão, reflete uma ferida nos direitos sociais, que compromete o ideal de dignidade. Neste sentido, Schwarz (2014, p. 79) reitera:

Caberia perguntarmo-nos se temos, de fato, tal concepção de dignidade humana. Sua definição não parece haver sido alcançada, até o momento, senão de forma negativa e indireta, considerando-se, assim, expressão da dignidade humana justamente uma série de direitos e expectativas materiais cuja violação concreta representaria, concomitantemente, a violação da dignidade humana. A par desse evidente círculo vicioso, essa definição indireta poderia ser enunciada nos seguintes termos gerais - a dignidade humana consiste, basicamente, naquilo que seria violado:

a) Se fossem subtraídos, à pessoa, os bens indispensáveis para a vida e/ou as liberdades mínimas;

b) Se é imposta à pessoa profunda e duradoura dor física e/ou psíquica evitável, ou se lhe é negado ou reduzido o próprio status de sujeito de direito.

(...)

Nesse contexto, o núcleo do princípio da dignidade não supõe apenas garantir a proteção da dignidade humana no sentido de assegurar para a pessoa, de forma genérica e abstrata, um tratamento não degradante, tampouco significa o simples oferecimento de garantias à integridade física ou psíquica do ser humano: nesse ambiente, de um renovado humanismo, a vulnerabilidade humana será tutelada de forma prioritária onde quer que se manifeste, e como se manifeste, de modo que sempre terão preferência os direitos e as necessidades de certos 
grupos sociais considerados, de uma forma ou de outra, mais vulneráveis, e que estão, assim, a exigir uma proteção especial: as crianças e os adolescentes, os idosos, os portadores de deficiências físicas ou mentais, os consumidores, os trabalhadores, os desempregados, os pobres e os membros de minorias étnico-raciais, entre outros. (2014, p.81)

A erradicação do trabalho escravo fere a dignidade da pessoa humana, uma vez que submete o obreiro a condições ínfimas de sobrevivência, em um patamar aquém do mínimo indispensável para uma vida digna. Desse modo, o conceito de trabalho em situação análoga à de escravo, apreendido pelo Direito do Trabalho deve abarcar todo o labor que desrespeite a dignidade da pessoa humana.

O estudo do Direito do Trabalho é essencial como instrumento de efetivação da dignidade da pessoa humana no mundo contemporâneo. Nesse sentido, é imperioso afirmar que todo o arcabouço jurídico-trabalhista preza pelo trabalho digno, realizado com a observância dos direitos fundamentais trabalhistas, assecuratórios do patamar mínimo existencial, sem o qual não há relação de trabalho digna. É a partir do conceito de trabalho digno que se examina o trabalho em condições análogas à de escravo, sob a perspectiva do ramo justrabalhista. Por fim, cumpre destacar a importância do elastecimento do conceito para coibir práticas degradantes e aviltantes da mão-de-obra, com o intuito de realizar efetivamente os propósitos do Estado Democrático de Direito Brasileiro, fundado no respeito à dignidade da pessoa humana.

Consoante Cambi (2009, p.30), temos que:

“A efetivação dos direitos humanos-fundamentais é resultado de duras
e difíceis conquistas sociais. Não traduzem uma história linear, nem a
história de uma causa perdida, mas a história da luta dos direitos a
partir da superação das graves diferenças entre os sujeitos de direitos,
discriminados, indevidamente, como objetos (como na escravidão dos
negros) ou seres de menor dignidade (como forma ou são as práticas
do nazismo, do sexismo, do racismo, da homofobia, da xenofobia e de
outras formas de intolerância).”

Nesse ínterim, importante salientar o que dispõe a Constituição da República Federativa do Brasil de 1988 em relação ao princípio da dignidade da pessoa humana, considerando que se trata de um dos princípios norteadores de todo ordenamento jurídico, assim como a valorização do trabalho.

Neste sentido, preceitua o art. $1^{\circ}$ da CR/88: 
Art. $1^{\circ}$ A República Federativa do Brasil, formada pela união indissolúvel dos Estados e Municípios e do Distrito Federal, constituise em Estado Democrático de Direito e tem como fundamentos:

III - a dignidade da pessoa humana;

IV - os valores sociais do trabalho e da livre iniciativa (...)

Denota-se uma proteção dos direitos trabalhistas pela Constituição da República Federativa do Brasil de 1988, a fim de estender os direitos fundamentais às relações de trabalho. Essa proteção é oriunda de um constitucionalismo moderno, denominado neoconstitucionalismo, em que prevalece a superação de um ordenamento jurídico extremamente formal, valorizando conceitos como da razoabilidade, senso comum e interesse público.

A dignidade da pessoa humana e a valorização do trabalho estão diretamente relacionadas ao direito do homem, sendo considerados direitos fundamentais tutelados pelo Estado brasileiro através de tratados internacionais de direitos humanos.

Neste ínterim, torna-se relevante distinguir a dignidade como fundamento da República Federativa do Brasil, da dignidade como princípio, como será exposto adiante.

Segundo $\operatorname{Kant}^{3}$ (2001, p.20), dignidade é uma coisa que está acima de todo preço, não permitindo ser substituída por algo equivalente, que constitui uma condição para algo que seja um fim em si mesmo e que possui um valor interno. Está relacionada a uma construção de ordem moral.

Este conceito é comungado pela Declaração Universal dos Direitos Humanos, que reconhece que a razão é a causa justificadora da dignidade e de direitos.

Percebe-se, portanto, que o princípio da dignidade da pessoa humana impõe ao Estado um dever de abstenção, que se exprime na obrigação dos órgãos estatais de não praticar atos contrários à dignidade pessoal, e também uma obrigação positiva, no sentido de impor aos agentes públicos o dever de adotar condutas e estratégias, com vistas a tornar efetiva e resguardar a dignidade pessoal dos indivíduos.

Considerando que a dignidade promove a inclusão e a existência digna, nos valemos dos apontamentos do sociólogo Zygmunt Bauman (1999, p. 30), que afirma que há o padrão da diferenciação simétrica, em que “a diferença entre os padrões é aquela entre a dignidade e a

\footnotetext{
${ }^{3}$ Cf. KANT, Immanuel. Fundamentos da metafísica dos costumes. Tradução de Lourival de Queiroz Henkel. Rio de Janeiro: Ediouro, (20??). p. 62-78; COMPARATO, Fábio Konder. A afirmação histórica dos direitos humanos. 2. ed. rev. e ampl. São Paulo: Saraiva, 2001. p.20.
} 
humilhação, a condição humana e a sua perda”. Logo, a escravidão contemporânea configura a perda da condição humana, uma vez que retira a dignidade e é permeada constantemente pela humilhação.

Por conseguinte, cabe ao Estado não apenas conferir ao homem a oportunidade de acesso ao trabalho, mas também cuidar para que o trabalho seja executado em condições dignas, considerando que o trabalho ocupa posição de destaque, assegurando a sobrevivência do indivíduo e garantindo a própria dignidade. A partir desse raciocínio, entende-se que a dignidade garante o trabalho, e o trabalho garante a própria dignidade.

Deste modo, a fim de trancar a escravidão na escuridão do passado, seja necessária a humanização do próprio ser humano enquanto empregador, pois assim, talvez seria possível a geração de empregos dignos, condizentes com a legislação trabalhista e com a qualidade de vida almejada pelos trabalhadores vítimas da escravidão moderna.

\section{Considerações Finais}

Diante dos argumentos apresentados, o trabalho escravo contemporâneo apenas será erradicado do país, quando os direitos da personalidade enquanto direitos fundamentais dos trabalhadores forem observados em sua integralidade. O ideal é que seja disseminada uma cultura antiescravocrata, para que a escravidão seja banida da sociedade brasileira. No entanto, não basta apenas a legislação punir severamente os “coronéis contemporâneos”, mas sim, há a necessidade de se implementar políticas públicas promovidas pelo Estado a fim de conscientizar a sociedade.

Ressalte-se que a partir da perspectiva dos direitos fundamentais há a possibilidade de mitigar essa realidade através de práticas processuais contemporâneas, como o neoconstitucionalismo e o neoprocessualismo, ambos, mecanismos de interpretação e aplicação da legislação e dos princípios fundamentais ao caso concreto, sob a ótica da realidade de cada indivíduo, com o objetivo de satisfazer os anseios dos indivíduos de forma justa e inclusiva.

Entende-se de extrema relevância o viés constitucional aplicado ao direito do trabalho, considerando que a partir dessa perspectiva há a possibilidade de contemplar diversos aspectos da escravidão contemporânea, entre eles, o quanto essa prática afeta a dignidade da pessoa humana, reduzindo o indivíduo escravizado a mera mercadoria.

Considerando que o exercício do trabalho possibilita o ser humano de satisfazer necessidades, realizar sonhos, e de reafirmá-lo perante uma sociedade capitalista, o trabalho é 


\section{O TRABALHO ESCRAVO CONTEMPORÂNEO ANALISADO SOB A -PERSPECTIVA DA DIGNIDADE DA PESSOA HUMANA ENQUANTO DIREITO DA PERSONALIDADE}

instrumento de realização plena da dignidade humana. Dessa forma, não há que se aceitar a escravidão como realidade, pois, ela contraria os objetivos e princípios do trabalho, além de impedi-lo de cumprir sua função social.

No entanto, em que pese a relevância da discussão do tema, a prática do trabalho escravo só será aniquilada através de ações que se pautem na consolidação dos princípios fundamentais da dignidade, da liberdade, da justiça social, da valorização social do trabalho e da igualdade, a fim de concretizar uma dignidade pautada no labor sadio e enriquecedor do ser humano não simplesmente no que tange aos bens materiais, mas também àqueles bens subjetivos, atrelados à autoestima, à realização profissional e à liberdade.

A partir daí, superada a necessidade de subordinação humilhante e da hierarquia entre patrão e empregados, de forma a admitir que estes sejam escravizados, simplesmente porque recebem para trabalhar, poder-se-á dizer que se vive em uma sociedade garantidora de direitos, em que garante-se a liberdade de exercício da atividade econômica a fim de obter riqueza, mas que também atenta-se à harmonia social, tendo como foco o trabalhador e sua dignidade.

Diante dos argumentos apresentados, o ideal no que tange à garantia dos direitos da personalidade e dos direitos fundamentais, quando se estabelece a dignidade da pessoa humana e a valorização social do trabalho como fundamento da república e os demais princípios constitucionais como direitos fundamentais dos trabalhadores, não visa a supressão da liberdade e das de riquezas dos empregadores, tampouco a redução de seus lucros, mas sim, objetiva uma sociedade justa, em que empregadores enxerguem seus empregados como semelhantes e também como riquezas, indispensáveis à produção.

Dessa forma, a luta para que os direitos trabalhistas sejam respeitados conforme a interpretação benéfica aos trabalhadores, nada mais almeja que a exploração e o enriquecimento a partir de trabalhadores miseráveis sejam inconcebíveis, pois, assim será possível a realização da justiça social a todos os cidadãos, satisfazendo o ideal de dignidade humana de uma forma plena.

\section{Referências}

ALEXY, Robert. Teoria dos direitos fundamentais. Tradução Virgílio Afonso da Silva. São Paulo: Malheiros, 2008.

ARAÚJO, Luiz Alberto David. A proteção constitucional da própria imagem. 2. ed. São Paulo: Verbatim, 2013, p. 38. 
BAUMAN, Zygmunt. Globalização: as consequências humanas. Rio de Janeiro: Jorge Zahar Ed., 1999.

BELTRÃO, Silvio Romero. Direitos da personalidade: de acordo com o novo código civil. São Paulo: Atlas, 2005, p. 27.

BITTAR, Carlos Alberto. BITTAR FILH, Carlos Alberto. Os direitos da personalidade. 7. ed. Rio de Janeiro: Forense Universitária, 2008.

BULOS, Uadi Lammêgo. Curso de Direito Constitucional. São Paulo: Saraiva, 2007.

CAMBI, Eduardo. Neoconstitucionalismo e neoprocessualismo: direitos fundamentais, políticas públicas e protagonismo judiciário. - São Paulo: Editora Revista dos Tribunais, 2009.

CASSAR, Vólia Bomfim. Direito do Trabalho. Rio de Janeiro: Impetus, 2008.

CONSOLIDAÇÃO DAS LEIS TRABALHISTAS. Disponível em http://www.planalto.gov.br/ccivil_03/decreto-lei/Del5452.htm. Acesso em 15/07/2017.

COMPARATO, Fábio Konder. A afirmação histórica dos direitos humanos. 2. ed. rev. e ampl. São Paulo: Saraiva, 2001. p.20.

DELGADO, Gabriela Neves. Direito fundamental ao trabalho digno. São Paulo: LTr, 2006.

DELGADO, Maurício Godinho. Princípios de direito individual e coletivo do trabalho. - 4. ed.São Paulo: LTr, 2013.

GONÇALVES FILHO, José Moura. Prefácio. In: COSTA, Fernando Braga da. Homens Invisíveis: Relatos de uma humilhação social. São Paulo: Editora Globo, 2004.

JOÃO PAULO II. Carta Encíclica Laborem exercens (Sobre o trabalho humano, por ocasião do nonagésimo aniversário da Rerum Novarum). São Paulo: Loyola, 1981.

LEÃO XIII, Papa. Carta Encíclica Rerum Novarum (Sobre a condição dos operários). Petrópolis: vozes, 1973.

MACHADO, Sidnei. Trabalho escravo e trabalho livre no Brasil: alguns paradoxos históricos do direito do trabalho, 2012.2015 http://ojs.c3sl.ufpr.br/ojs2/index.php/direito/article/view/1766/1463>. Acesso em 08 out. 2015.

MAIOR, Jorge Luiz Souto. O Direito do Trabalho como instrumento de justiça social. São Paulo: LTr, 2001. 


\section{O TRABALHO ESCRAVO CONTEMPORÂNEO ANALISADO SOB A -PERSPECTIVA DA DIGNIDADE DA PESSOA HUMANA ENQUANTO DIREITO DA PERSONALIDADE}

MELLO, Cláudio Ari. Contribuição para uma teoria híbrida dos direitos de personalidade. In: SARLET, Ingo Wolfgang. O novo código civil e a constituição. Porto Alegre: Livraria do Advogado, 2003.

MINISTÉRIO DO TRABALHO E EMPREGO. Disponível em $<$ http://www.mte.gov.br/index.php/fiscalizacao-combate-trabalho-escravo $>$. Acesso em 02 out. 2015.

MIRAGLIA, Lívia Mendes Moreira. Trabalho escravo contemporâneo: conceituação à luz do princípio da dignidade da pessoa humana. São Paulo: Ltr, 2011.

MONTEIRO, Mariah. A escravidão contemporânea do setor sucro-alcooleiro. Disponível em $<$ http://www.criticadodireito.com.br/todas-as-edicoes/numero-1-volume-17/a-escravidaocontemporanea-do-setor-sucro-alcooleiro>. Acesso em 05 out. 2015.

NUNES, Rizzatto. O princípio constitucional da dignidade da pessoa humana: doutrina e jurisprudência. São Paulo: Saraiva, 2007.

\section{ORGANIZAÇÃO DAS NAÇÕES UNIDAS. ONU. Declaração sobre o Direito ao}

Desenvolvimento. Resolução 41/128 da Assembleia das Nações Unidas. Dez. 1986.

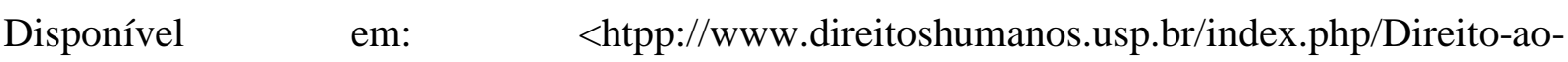
desenvolvimento/declaração-sobre-o-direito-ao-desenvolvimento.html>. Acesso em: 30 de maio de 2016.

SAKAMOTO, Leonardo. A economia do trabalho escravo no Brasil contemporâneo. In: Cerqueira, G. C. et al (orgs.). Trabalho escravo contemporâneo no Brasil: contribuições críticas para sua análise e denúncia. Rio de Janeiro: Editora UFRJ. 2008.

SCHWARZ, Rodrigo Garcia. Terra de trabalho, terra de negócio: o trabalho escravo contemporâneo na perspectiva (da violação) dos direitos sociais. São Paulo: LTr, 2014.

SARLET, Ingo Wolfgang. Dignidade da pessoa humana e direitos fundamentais na Constituição Federal de 1988. 9. ed., revista e ampliada. Porto Alegre: Livraria do Advogado Editora, 2012.

SARMENTO, Daniel. Direitos fundamentais e relações privadas . Rio de Janeiro: Lumen Júris, 2004, p. 111.

SENTO-SÉ. Jairo Lins de Albuquerque. Trabalho Escravo no Brasil. São Paulo: LTr, 2000.

SILVA, Marcello Ribeiro. Trabalho análogo ao de escravo rural no Brasil do século XXI: novos contornos de um antigo problema. Goiânia, 2010. P. 68-79.

TEPEDINO, Gustavo. A tutela da personalidade no ordenamento civil-constitucional brasileiro: Temas de direito civil. 3. ed. Rio de Janeiro: Renovar, 2004, p. 25. 
